\title{
Jurist-Diction
}

Volume 4 No. 5 September 2021

\section{Pengaturan Perlindungan Satwa Terancam di Daerah Konflik Bersenjata}

\author{
Yunia Utami Indah Haloho \\ yuniautamiindahhaloho@gmail.com \\ Universitas Airlangga
}

How to cite:

Yunia Utami Indah Haloho, 'Pengaturan Perlindungan Satwa Terancam di Daerah Konflik Bersenjata' (2021) Vol. 4 No. 5 JuristDiction.

\section{Histori artikel:}

Submit 17 Juli 2021;

Diterima 15 Agustus 2021;

Diterbitkan 1 September 2021.

DOI:

10.20473/jd.v4i5.29834

p-ISSN: $2721-8392$

e-ISSN: $2655-8297$

\section{Abstract}

Humans are often regarded as the only victims that are affected by the armed conflicts. But apparently not only humans, there are also the other living creatures that become the victims of the armed conflicts those are animals included threatened animals. Threatened animals are part of biological diversity that have a high extinction risk level because of the small amount of their populations that requires intensive protection. There are numbers of armed conflicts that happened in the world states where the threatened animals become the victims of it. Threatened animals have to experience the declining of their populations due to the destruction of their habitat, illegal trades of them for financing the conflicts, illegal poaching for their meats, or killed by the weapons that used during the conflicts. The results of this research demonstrates that the International Law through the International Environmental Law and International Humanitarian Law have indirectly provided the regulations about threatened animals in the armed conflict area.

Keywords: Threatened Animals; Protection; Regulation.

\begin{abstract}
Abstrak
Manusia sering kali dianggap sebagai satu-satunya korban yang terdampak akibat terjadinya konflik bersenjata. Namun ternyata bukan hanya manusia saja, terdapat makhluk hidup lain yang juga turut menjadi korban akibat dari konflik bersenjata di suatu wilayah negara yaitu satwa termasuk satwa terancam. Satwa terancam yang merupakan bagian dari keanekaragaman hayati memiliki tingkat risiko kepunahan yang tinggi karena populasinya yang sedikit sehingga memerlukan perlindungan yang intensif. Terdapat beberapa konflik bersenjata yang terjadi di berbagai negara di dunia di mana satwa terancam menjadi salah satu korban dari konflik tersebut. Satwa terancam mengalami pengurangan jumlah populasi akibat rusaknya habitat mereka, perdagangan satwa terancam tersebut untuk membiaya konflik, perburuan liar satwa terancam untuk dikonsumsi, atau terbunuhnya satwa terancam akibat terkena serangan senjata yang digunakan dalam konflik. Hasil penelitian ini menunjukkan bahwa Hukum Internasional melalui Hukum Lingkungan Internasional dan Hukum Humaniter Internasional telah sama-sama memberikan pengaturan terkait perlindungan satwa terancam di daerah konflik bersenjata walaupun bukan merupakan pengaturan yang mengatur secara langsung.

Kata Kunci: Satwa Terancam; Perlindungan; Pengaturan.
\end{abstract} Copyright (c) 2021 Yunia Utami Indah Haloho 


\section{Pendahuluan}

Konflik bersenjata dapat memberikan efek beragam kepada satwa, tentara dan penduduk yang kelaparan dapat memburu satwa untuk dagingnya, senjata yang digunakan dalam konflik dapat membunuh satwa, kelompok bersenjata yang membiayai aktivitas militer yang mereka lakukan dengan berburu dan memperdagangkan secara ilegal satwa-satwa seperti gajah dan badak karena gading dan cula mereka, setidaknya begitulah hasil penelitian dari Joshua Dashkin dari Yale University dan Robert Pringle dari Princeton University, Amerika Serikat yang juga menemukan bahwa bahwa semakin tinggi jumlah konflik yang terjadi, populasi satwa liar menurun. ${ }^{1}$

Konflik bersenjata yang bekecamuk di wilayah Negara Republik Demokratik Kongo yang sudah terjadi sejak puluhan tahun yang lalu ternyata tidak hanya berdampak langsung kepada kondisi kehidupan manusia saja tetapi juga terhadap satwa. Setidaknya dilaporkan akibat dari perang sipil di Negara Kongo tersebut telah menyebabkan populasi Gorilla Grauer (Grauer's Gorilla), satwa endemik yang hanya ada di Kongo, dan populasi Gorilla Gunung (Mountain Gorilla) mengalami penurunan jumlah yang sangat drastis. Kurang dari 3.800 tersisa di alam liar, turun sebanyak 77\% dari 17.000 ditahun 1998 untuk Gorilla Grauer dan kurang dari 700 Gorilla Gunung yang tersisa dan hidup di alam liar. ${ }^{2}$

Kasus yang sama yang terjadi di Negara Mozambik. Pemerintah dan kelompok-kelompok penyebab konflik menggunakan Taman Nasional Gorongosa selama konflik antara tahun 1977 dan 1992. Para peneliti menemukan bahwa konflik bersenjata ini telah memusnahkan populasi mamalia besar di taman nasional tersebut. Jumlah gajah menurun hingga 75 persen di awal tahun 2000, dan jumlah kuda nil, hingga zebra juga turut berkurang. ${ }^{3}$ Masih terdapat beberapa kasus-kasus

\footnotetext{
${ }^{1}$ Mongobay.com, 'Wars kill wildlife in Africa's protected areas, study finds' (Mongobay. com, 2018) <https://news.mongabay.com/2018/01/wars-kill-wildlife-in-africas-protected-areasstudy-finds/> accessed 15 November 2019.

${ }^{2}$ Katie Reilly, 'The Congo's Civil War Is Wiping Out Gorilla Populations' (Time.com, 2016) $<$ https://time.com/4282616/the-congos-civil-war-is-wiping-out-gorilla-populations/> accessed 15 Agustus 2019.

${ }^{3}$ Mongobay.com, Loc.Cit.
} 
serupa, contoh lain yaitu pembunuhan ilegal terhadap gajah pada konflik bersenjata di Sri Lanka antara pemerintah dengan kelompok bersenjata dalam rentang tahun 1984 hingga $1999 .{ }^{4}$

Kasus-kasus di atas memiliki kesamaan di mana terdapat konflik bersenjata yang menyebabkan berkurangnya populasi satwa. Satwa yang mengalami pengurangan populasi akibat konflik bersenjata tersebut merupakan satwa yang termasuk dalam golongan satwa terancam. Satwa terancam sendiri merupakan satwa yang diberi perlindungan yang khusus dan lebih komprehensif. Alasan diberlakukannya perlindungan yang khusus dan komprehensif adalah karena satwa terancam tersebut dari segi populasi merupakan golongan yang paling sedikit jumlahnya di dunia dan menghadapi risiko kepunahan yang tinggi.

Satwa terancam merupakan bagian dari keanekaragaman hayati. Keanekaragaman hayati diartikan sebagai jumlah jenis. Makin besar jumlah jenis, makin besar pula keanekaragaman hayati. Melalui evolusi dengan terus-menerus terjadilah spesies baru, sebaliknya dengan terus menerus pula terjadi kepunahan jenis. Apabila laju terjadinya jenis baru lebih besar daripada kepunahan, maka keanekaragaman hayati bertambah, sebaliknya manakala laju kepunahan lebih besar, maka keanekaragaman hayati makin menurun. ${ }^{5}$ Apabila satwa terancam ini terus mengalami pengurangan jumlah maka laju kepunahan satwa ini semakin besar.

Konflik bersenjata yang turut mengambil bagian dalam penurunan jumlah populasi satwa terancam di beberapa negara tidak dapat diabaikan begitu saja. Seperti konflik-konflik yang telah disebutkan sebelumnya. Penurunan jumlah populasi satwa terancam tersebut dikhawatirkan akan turut membawa satwa terancam menuju kepunahan mengingat telah banyak faktor yang membahayakan keberadaan dari satwa terancam tersebut. Terlebih bagi satwa terancam yang merupakan satwa endemik suatu negara. Namun, terlepas dari satwa terancam

${ }^{4}$ Joseph P, Dudley, [et., al.], 'Effects of War and Civil Strife on Wildlife and Wildlife Habitats' (2002) 16 Conservation Biology.[321].

${ }^{5}$ Otto Soemarwoto, Indonesia dalam Kancah Isu lingkungan Global (Gramedia Pustaka Utama 1991). [81]. 
tersebut berpotensi punah atau tidak, satwa terancam merupakan organisme atau makhluk hidup yang harus dilindungi keberadaannya.

Berdasarkan uraian diataslah, maka penelitian ini akan membahas terkait perlindungan satwa khususnya satwa terancam di daerah konflik bersenjata berdasarkan pengaturan Hukum Internasional, karena konflik bersenjata yang terjadi telah menyebabkan terganggunya eksistensi satwa terancam yang merupakan bagian dari keanekaragaman hayati dunia dan sebagaimana tercantum dalam pembukaan Konvensi Keanekaragaman Hayati tahun 1992, bahwa kelestarian keanekaragaman hayati harus menjadi perhatian dari umat manusia. Keanekaragaman hayati tersebut juga merupakan salah satu fokus dari Hukum Internasional.

\section{Pengaturan Perlindungan Satwa Terancam Di Daerah Konflik Bersenjata Berdasarkan Hukum Lingkungan Internasional}

Hukum Lingkungan Internasional merupakan salah satu cabang dari Hukum Internasional publik dimana hukum ini berfokus pada upaya untuk mengendalikan pencemaran lingkungan dan menipisnya sumber daya alam di bumi dalam kerangka kerja yang berdasarkan prinsip-prinsip sustainable development atau pembangunan yang berkelanjutan. Pada prinsipnya tindakan pengaturan Hukum Lingkungan Internasional sesuai untuk hal-hal berikut: ${ }^{6}$

a. Persoalan-persoalan pencemaran dan kontaminasi samudera-samudera dan atmosfer, karena hal ini mungkin merupakan objek dari pemanfaatan umum, sebagian lagi karena ketidakmampuan dalam hal-hal tertentu melokalisir pengaruh-pengaruh dari zat-zat pencemaran dan kontaminasi;

b. Spesies-spesies yang dilindungi dan suaka-suaka alam, dengan alasan bahwa hal ini merupakan warisan bersama umat manusia. Perjanjian-perjanjian internasional mungkin perlu untuk mengawasi ekspor, impor, dan juali beli spesies-spesies yang terancam punah;

c. Penipisan sumber-sumber daya laut, mengingat ketergantungan manusia terhadap laut sebagai sumber protein;

d. Pemantauan perubahan-perubahan dalam atmosfer bumi, iklim, dan kondisikondisi musim;

e. Pemantauan standar-standar internasional terhadap baku mutu lingkungan;

${ }^{6}$ J.G. Starke, Pengantar Hukum Internasional Edisi 2 (Sinar Grafika 1989).[538]. 
f. Pengawasan timbal balik dan pengendalian atas operasi-operasi industri tertentu di semua negara, dimana operasi-operasi tersebut dapat membahayakan lingkungan, untuk menghilangkan rangsangan-rangsangan guna memperoleh keuntungan kompetitif dengan mengabaikan akibat-akibat dari prosesproses yang membahayakan lingkungan. Prosedur-prosedur untuk tindakan internasional dalam kasus ini telah diberikan oleh konvensi-konvensi buruh internasional, yang mana salah satu tujuannya untuk menjamin bahwa kompetisi ekonomi antar negara-negara tidak menghalangi realisasi standar-standar yang layak bagi kondisi kerja.

Salah satu ruang lingkup pengaturan Hukum Lingkungan Internasional adalah pengaturan tentang spesies-spesies yang dilindungi dan suaka-suaka alam sebagai warisan bersama umat manusia. Satwa terancam merupakan golongan satwa yang termasuk dalam spesies-spesies yang dilindungi, sehingga juga termasuk dalam ruang lingkup Hukum Lingkungan Internasional. Hukum Lingkungan Internasional melalui pengaturannya juga turut memberikan perlindungan terhadap satwa terancam ini di daerah konflik bersenjata.

\section{Convention on Biological Diversity 1992}

Pengertian keanekaragaman hayati tercantum dalam Pasal 2 Convention on Biological Diversity tahun 1992: “'Biological diversity' means the variability among living organisms from all sources including, inter alia, terrestrial, marine and other aquatic ecosystems and the ecological complexes of which they are part: this includes diversity within species, between species and of ecosystem".?

Berdasarkan pasal tersebut keanekaragaman hayati merupakan keberagaman organisme atau makhluk hidup baik yang hidup di darat maupun di laut dan lingkungan ekologis di mana mereka menjadi bagiannya termasuk keberagaman dalam spesies itu sendiri, antar spesies dan ekosistem. Keberagaman organisme atau makhluk hidup yang dimaksudkan juga meliputi golongan satwa terancam sehingga konvensi ini juga meliputi satwa terancam. Konvensi ini merupakan salah satu konvensi yang dibuat oleh negara-negara anggota Perserikatan Bangsa-Bangsa (PBB). Konvensi ini merupakan "payung” bagi pengaturan internasional lain yang berkaitan dengan keanekaragaman hayati.

\footnotetext{
${ }^{7}$ Convention on Biological Diversity 1992.
} 
Walaupun konvensi ini tidak secara langsung mengatur perlindungan terhadap satwa terancam namun pada pembukaan konvensi ini dinyatakan dengan tegas bahwa merupakan hal yang penting untuk mencegah dan mengatasi penyebab pengurangan yang nyata atau hilangnya keanekaragaman hayati pada sumbernya. Keanekaragaman hayati yang dalam hal ini termasuk satwa terancam merupakan sesuatu yang harus dijaga dan dilestarikan keberadaannya jangan sampai berkurang jumlahnya atau bahkan menghilang dari muka bumi. Termasuk pengurangan jumlah populasi bahkan lenyapnya dari muka bumi yang diakibatkan oleh konflik bersenjata yang berkecamuk di suatu wilayah negara. Konvensi mengamanatkan untuk dilakukan konservasi dalam rangka pelestarian keanekaragaman hayati termasuk satwa terancam yang dapat dilakukan dengan metode konservasi In-situ seperti yang diatur dalam pasal 8 konvensi dan konservasi Ex-situ yang diatur dalam pasal 9 konvensi. Konservasi In-situ adalah konservasi ekosistem dan habitat alami serta pemeliharaan dan pemulihan populasi jenis-jenis berdaya hidup dalam lingkungan alaminya, dan dalam hal jenis-jenis terdomestifikasi atau budidaya, di dalam lingkungan tempat sifat-sifat khususnya berkembang. Jenis kegiatan konservasi insitu adalah kebun binatang, taman safari, kebun botani dan museum. ${ }^{8}$ Konservasi Ex-situ adalah konservasi keanekaragaman hayati di luar habitat alaminya, jenis kegiatan konservasi ex-situ adalah cagar alam dan suaka margasatwa. ${ }^{9}$

Selain itu terdapat salah satu cara lain untuk melakukan perlindungan terhadap keanekaragaman hayati termasuk satwa terancam menurut konvensi ini tercantum dalam Pasal 14 huruf e:

"Promote national arrangements for emergency responses to activities or events, whether caused naturally or otherwise, which present a grave and imminent danger to biological diversity and encourage international cooperation to supplement such national efforts and, where appropriate and agreed by the States or regional economic Integration organizations concerned, to establish joint contingency plans".

\footnotetext{
${ }^{8}$ Soekotjo, 'Konservasi Ex-situ Cendana: Aplikasi dan Tantangannya' (2001) 5 Berita Biologi.[515].

${ }^{9}$ ibid.
} 
Berdasarkan pasal tersebut harus ada pengaturan terkait dengan tindakan darurat yang harus diambil ketika terdapat kegiatan-kegiatan atau kejadian-kejadian yang sekiranya dapat membahayakan atau mengancam keanekaragaman hayati dan dapat dilakukan kerjasama internasional dalam rangka melakukan tindakan darurat tersebut apabila disetujui oleh negara-negara lain. Jika dikaitkan dengan keberadaan satwa terancam di daerah konflik bersenjata maka berdasarkan pasal tersebut sudah seharusnya diambil tindakan darurat terhadap kegiatan-kegiatan dan kejadian-kejadian yang membahayakan dan mengancam satwa terancam di daerah konflik bersenjata.

\section{Convention on International Trade in Endangered Species of Wild Fauna and}

\section{Flora 1973 (CITES)}

Konvensi ini merupakan konvensi terkait keanekaragaman hayati lain di bawah PBB yang berfokus pada perlindungan spesies baik fauna maupun flora dari perdagangan internasional yang sekiranya membahayakan keberlangsungan hidup mereka. CITES merupakan konvensi yang ditujukan untuk mengontrol dan mencegah perdagangan satwa terancam dan produk yang merupakan produk turunannya. ${ }^{10}$ Konvensi ini mengklasifikasikan spesies, dalam hal ini termasuk satwa terancam, dengan didasarkan pada status terancam spesies tersebut dalam beberapa daftar lampiran: spesies dalam lampiran pertama adalah yang paling terancam dan menjadi subjek dari pengaturan perdagangan yang paling ketat; spesies dalam lampiran kedua sejauh ini tidak terancam, tetapi memiliki risiko menjadi terancam apabila tidak adanya pengaturan terkait perdagangan; dan spesies dalam lampiran ketiga adalah spesies yang diawasi oleh otoritas nasional dalam hal pencegahan dan pembatasan eksploitasi satwa tersebut. ${ }^{11}$

Mekanisme perlindungan satwa terancam melalui pengaturan CITES adalah dengan mekanisme izin dan sertifikasi yang harus dilakukan oleh pihak yang

\footnotetext{
${ }^{10}$ Patricia Birnie, [et., al.], International Law and the Environment (Oxford University Press 2009).[685].

${ }^{11}$ Philippe Sands, [et.,al.], Documents in International Environmental Law (Cambridge University Press 2004).[661].
} 
hendak melakukan perdagangan di bawah pengawasan otoritas nasional. ${ }^{12}$ Sehingga sebenarnya perdagangan satwa terancam bukan tidak boleh $100 \%$ dilakukan hanya saja dilarang apabila perdagangan yang dilakukan itu sekiranya membahayakan atau tidak sesuai dengan prinsip keberlanjutan dalam Hukum Lingkungan Internasional.

Dikaitkan dengan satwa terancam di daerah konflik bersenjata, terdapat kasus di mana cula yang merupakan bagian dari tubuh badak yang termasuk dalam golongan satwa terancam di Afrika Selatan diperjualbelikan secara ilegal guna membeli senjata untuk perang. ${ }^{13}$ Saat hendak mengambil culanya badak kerap kali dibunuh terlebih dahulu. Sehingga mengakibatkan banyaknya badak yang harus mati akibat dari hal tersebut dan dapat dipastikan penurunan jumlah badak yang pasti terjadi. Seharusnya perlindungan satwa terancam berdasarkan konvensi ini harus dilakukan agar satwa terancam tidak lagi diperjualbelikan secara ilegal dalam kondisi apapun.

\section{ASEAN Agreement on The Conservation of Nature and Natural Resources} 1985

Satwa terancam juga diatur dalam pengaturan yang bersifat regional termasuk dalam ASEAN Agreement on The Conservation of Nature and Natural Resources ini. Perjanjian regional ASEAN ini diadopsi di Malaysia pada tanggal 9 Juli $1985 .{ }^{14}$ Pasal 5 ayat (1) dan (2) perjanjian ini berbunyi:

(1) Appendix I to this Agreement shall list endangered species recognized by the Contracting Parties as of prime importance to the Region and deserving special attention. The Appendix shall be adopted by a meeting of the Contracting Parties; Accordingly, Contracting Parties shall, wherever possible,

(a) prohibit the taking of these species, except for exceptional circumstances by special allowance from the designated authorities of the Contracting Parties;

\footnotetext{
${ }^{12}$ ibid.

${ }^{13}$ Maya Wei-Hass, "The Animal Cost of War" (Smithsonianmag.com 2018) <https://www. smithsonianmag.com/science-nature/animal-cost-of-war-180967806/> accessed 15 September 2019.

${ }^{14}$ Centre of International Law National University of Singapore, 'Agreement on The Conservation of Nature and Natural Resources' (Centre of International Law National University of Singapore, $2009<\mathrm{https}$ ://cil.nus.edu.sg/databasecil/1985-agreement-on-the-conservation-of-natureand-natural-resources/> accessed 15 september 2019.
} 
(b) regulate the trade in and possession of specimens and products of those species accordingly;

(c) especially protect habitat of those species by ensuring that sufficient portions are included in protected areas;

(d) take all other necessary measures to improve their, conservation status, and restore their populations to the highest possible level.

(2) Each Contracting Party shall, whenever Possible, apply the above measures to species endangered at national level. ${ }^{15}$

Berdasarkan ketentuan pasal di atas, spesies termasuk di dalamnya satwa terancam harus diberikan perlindungan khusus seperti pelarangan pengambilannya kecuali atas izin otoritas yang berwenang, mengatur tentang perdagangannya dan produk turunannya, memberikan perlindungan terhadap habitatnya, mengambil tindakan untuk mengembalikan populasi mereka sebisa mungkin hingga ke level tertinggi. Perjanjian ini juga mencantumkan daftar satwa terancam dalam lampirannya. ${ }^{16}$ Terdapat dua negara di Asia Tenggara yang wilayahnya sering berkecamuk konflik bersenjata internal yaitu Kamboja dan Myanmar. Komitmen kedua negara tersebut untuk menjalankan ketentuan perjanjian ini terkait perlindungan satwa terancam diuji saat terjadi konflik bersenjata di negara mereka. Namun tidak menutup kemungkinan terjadi konflik bersenjata di wilayah negara lain di kawasan Asia Tenggara.

\section{European Union Council Directive 92/43/EEC 1992}

Merupakan salah satu regulasi regional lain yang dikeluarkan oleh Uni Eropa yang memiliki nama lengkap the Council Directive 92/43/EEC of 21 May 1992 on the conservation of natural habitats and of wild fauna and flora. Pengaturan ini hanya mengikat bagi negara-negara anggota Uni Eropa saja. Pengaturan ini juga mengatur mengenai perlindungan dan pelestarian satwa termasuk satwa terancam mengingat jumlahnya yang semakin meningkat. Pasal 12 paragraf 1 pengaturan ini berbunyi:

"Member States shall take the requisite measures to establish a system of strict protection for the animal species listed in Annex IV $(a)$ in their natural range, prohibiting:

\footnotetext{
${ }^{15}$ ASEAN Agreement on The Conservation of Nature and Natural Resources 1985.

${ }^{16}$ ASEAN Agreement on The Conservation of Nature and Natural Resources 1985.
} 
(a) all forms of deliberate capture or killing of specimens of these species in the wild;

(b) deliberate disturbance of these species, particularly during the period of breeding, rearing, hibernation and migration;

(c) deliberate destruction or taking of eggs from the wild;

(d) deterioration or destruction of breeding sites or resting places". ${ }^{17}$

Berdasarkan pasal tersebut satwa yang berada dalam daftar pada lampiran IV yang berdasarkan Pasal 1 huruf g merupakan satwa yang termasuk dalam golongan satwa terancam, harus mendapatkan perlindungan yang ketat dengan laranganlarangan yang sudah tercantum dalam pasal tersebut dari negara-negara anggota Uni Eropa. Tindakan-tindakan yang terdapat dalm ketentuan pasal tersebut merupakan tindakan yang mungkin saja terjadi saat adanya konflik bersenjata termasuk konflik bersenjata. Sehingga negara anggota harus mengemban kewajiban untuk memberlakukan kebijakan untuk memberikan perlindungan yang ketat atas satwa terancam di daerah konflik tersebut.

\section{Pengaturan Perlindungan Satwa Terancam Di Daerah Konflik Bersenjata Berdasarkan Hukum Humaniter Internasional}

Spesies termasuk satwa terancam hidup di wilayah negara dengan kondisi berbeda-beda. Terdapat satwa yang hidup di wilayah negara yang damai sehingga dapat hidup dan berkembang dan terdapat pula satwa terancam yang hidup di daerah konflik khususnya konflik bersenjata yang sangat membahayakan keberlangsungan hidup mereka.

Hukum Humaniter memang merupakan hukum yang mengatur tentang perang, namun hukum ini juga memperhatikan dan mengatur aspek lain baik secara langsung maupun tidak langsung dalam pengaturannya termasuk aspek lingkungan walaupun tidak banyak dan terperinci. Mengingat lingkungan menjadi salah satu komponen yang terdampak dalam suatu konflik bersenjata. Walaupun dalam pengaturan Hukum Humaniter tidak secara eksplisit memberikan pengaturan terkait perlindungan

\footnotetext{
${ }^{17}$ Council Directive 92/43/EEC of 21 May 1992 on the conservation of natural habitats and of wild fauna and flora.
} 
satwa terancam, namun aspek perlindungan terhadap lingkungan telah mencakup perlindungan terhadap satwa terancam dalam hukum ini karena lingkungan merupakan tempat dimana organisme hidup. Dalam pengertian yang lebih luas lagi, lingkungan termasuk di dalamnya air, udara, tanah, flora dan fauna. ${ }^{18}$ Berbahaya bagi lingkungan juga dapat berarti kehancuran total atau sebagian dari flora dan fauna. ${ }^{19}$

Berbeda dengan konflik bersenjata internasional, tidak terdapat banyak pengaturan terkait perlindungan lingkungan alam termasuk di dalamnya satwa terancam di daerah konflik bersenjata internal ini. Bahkan Protokol II yang merupakan pengaturan terkait konflik bersenjata internal pun tidak membahas mengenai hal ini. ${ }^{20}$ Tidak sebanyak pengaturan tentang perlindungan lingkungan di daerah konflik bersenjata internasional karena bahkan pengaturan terkait konflik bersenjata internal sendiri di dalam Hukum Humaniter Internasional pun memiliki bagian yang tidak banyak.

\section{Hague Convention IV 1907}

Salah satu pengaturannya terdapat pada The Hague Laws IV 1907 atau Hague Convention IV Laws and Customs of War on Land 1907 yang merupakan sumber Hukum Humaniter tertulis yang memiliki fokus pengaturan terkait cara berperang dan jenis senjata yang diperbolehkan untuk digunakan saat perang. ${ }^{21}$

Hague Convention 1907 secara khusus melarang tindakan-tindakan tertentu pada saat perang, salah satunya seperti dalam Pasal 23 huruf g Hague Convention 1907 yang berbunyi: “To destroy or seize the enemy's property, unless such destruction or seizure be imperatively demanded by the necessities of war". ${ }^{22}$

Berdasarkan ketentuan pasal tersebut Hukum Humaniter melarang tindakan menghancurkan properti lawan kecuali memang merupakan tuntutan dari perang.

\footnotetext{
${ }^{18}$ The English Environment Protection Act 1990

${ }^{19}$ Viola Vincze, 'The Role of Customary Principles of International Humanitarian Law in Environmental Protection' (2017) 2017 Pécs Journal of International and European Law.[20].

${ }^{20}$ Desy Churul Aini, [et., al.], 'Environmental Protection in Armed Conflict According to International Humanitarian Law’ (2018) 3 Tadulako Law Review.[18].

${ }^{21}$ C . De Rover, To Server and To Protect: Acuan Universal Penegakan HAM (Raja Grafindo Persada 2000).[100].

${ }^{22}$ Hague Convention 1907
} 
Selanjutnya dalam Pasal 55 konvensi yang sama yang berbunyi: "The occupying State shall be regarded only as administrator and usufructuary of public buildings, real estate, forests, and agricultural estates belonging to the hostile State, and situated in the occupied country. It must safeguard the capital of these properties, and administer them in accordance with the rules of usufruct", ${ }^{23}$

Istilah 'properti' dalam kedua ketentuan pasal tersebut diasumsikan mencakup sumber daya alam. ${ }^{24}$ Walaupun minimnya definisi resmi, konvensi memberikan indikasi cukup untuk mendukung pernyataan ini. ${ }^{25}$ Pasal 55 Hague Convention IV misalnya dengan jelas menetapkan hutan sebagai properti. Seperti yang diketahui hutan merupakan habitat tempat spesies termasuk satwa terancam hidup. Namun, ketentuan tersebut berlaku bagi konflik bersenjata internasional saja. ${ }^{26}$

\section{Geneva Convention 1949}

Selain itu terdapat pula pengaturan dalam Geneva Convention 1949 yang merupakan sekumpulan aturan Hukum Humaniter Internasional yang berfokus lebih kepada kondisi dari korban perang. ${ }^{27}$ Konvensi ini terdiri dari 4 konvensi dan dari semua Konvensi Jenewa 1949 hanya ada dua konvensi yang memiliki pengaturan terkait perlindungan lingkungan bahkan dengan perjanjian khusus dan konteks dari pendudukan militer. ${ }^{28}$ Salah satunya dalam Pasal 53 Geneva Convention IV 1949 yang berbunyi:

"Any destruction by the Occupying Power of real or personal property belonging individually or collectively to private persons, or to the State, or to other public authorities, or to social or co-operative organizations, is prohibited, except where such destruction is rendered absolutely necessary by military operations." ${ }^{29}$

Pengaturan pasal ini merupakan pengaturan lebih lanjut terkait perlindungan properti seperti pada pengaturan pada Hague Convention 1907. Sama seperti

${ }^{23}$ Hague Convention 1907

${ }^{24}$ Daniella Dam-De Jong, International Law and Governance of Natural Resources in Conflict and Post-Coflict Situations (Cambridge University Press 2015).[ 217].

${ }^{25}$ ibid.

${ }^{26}$ Dam-De Jong. Op.Cit.[.215].

${ }^{27}$ Desy Churul Aini, [et., al.].Op.Cit.[17].

${ }^{28}$ ibid.

${ }^{29}$ Geneva Convention IV 1949 
Hague Convention 1907, konvensi ini mengatur konflik yang merupakan konflik bersenjata internasional.

\section{Protocol I 1977}

Terdapat pengaturan dalam Protokol I 1977 tepatnya dalam Pasal 35 paragraf (3) yang berbunyi: "It is prohibited to employ methods or means of warfare which are intended, or may be expected, to cause widespread, longterm and severe damage to the natural environment", ${ }^{30}$

Kemudian dalam Pasal 55 protokol yang sama yang berbunyi:

1. Care shall be taken in warfare to protect the natural environment against widespread, longterm and severe damage. This protection includes a prohibition of the use of methods or means of werfare which are intended or may be expected to cause such damage to the natural environment and thereby to prejudice the health or survival of the population.

2. Attack against the natural environment by way of reprisals are prohibited. ${ }^{31}$ Protokol I 1977 di atas mengatur tentang larangan untuk melakukan serangan terhadap lingkungan alam. Lingkungan alam juga dapat merupakan habitat dari spesies termasuk satwa terancam sehingga melakukan serangan kepada lingkungan natural juga dapat berdampak pada spesies yang hidup di dalamnya termasuk satwa terancam. Terdapat beberapa pengaturan-pengaturan lain terkait dengan perlindungan lingkungan alam termasuk satwa terancam di daerah konflik bersenjata internasional ini.

\section{Protocol II 1977}

Protokol II 1977 ini merupakan protokol yang juga melengkapi Konvensi Jenewa 1949 seperti halnya Protokol I. Protokol ini secara signifikan meningkatkan perlindungan hukum bagi penduduk sipil dan korban luka, dan untuk pertama kali, menetapkan aturan-aturan kemanusiaan secara rinci yang berlaku ketika terjadi perang sipil atau konflik bersenjata internal. ${ }^{32}$ Namun, berbeda dengan Protokol I, protokol ini tidak mengatur mengenai aspek lingkungan pada saat konflik

\footnotetext{
${ }^{30}$ Protocol I 1977.

${ }^{31}$ Protocol I 1977.

${ }^{32}$ ICRC Blog, 'Protokol Tambahan I dan II Tahun 1977' (ICRC, 2012), <https://blogs.icrc. org/indonesia/protokol-tambahan-i-dan-ii-tahun-1977/> accessed 29 Desember 2019.
} 
bersenjata. ${ }^{33}$ Sehingga dapat dipastikan protokol ini juga tidak sampai mengatur perlindungan terhadap satwa khususnya satwa terancam.

5. Convention on the Prohibition of Military or Any Other Hostile Use of

\section{Environmental Modification Techniques 1977 (ENMOD 1977)}

Salah satu perjanjian internasional yang mengatur tentang perlindungan lingkungan di daerah konflik bersenjata ini adalah Convention on the Prohibition of Military or Any Other Hostile Use of Environmental Modification Techniques 1977 (ENMOD 1977). Konvensi ini ditandatangani pada 18 Mei 1977 di Jenewa terdiri dari 10 pasal dan lampiran. ${ }^{34}$ Peran utama ENMOD Convention 1977 terkait dengan perlindungan lingkungan di daerah konflik bersenjata termasuk konflik bersenjata internal adalah untuk mencegah penggunaan dari senjata pemusnah massal dalam perang. ${ }^{35} \mathrm{Hal}$ ini dibuktikan oleh proyek Sunshine di tahun 2000, yang menguji ENMOD Convention 1977 sebagai sarana baru untuk mencegah penggunaan dari senjata pemusnah massal, khususnya senjata biologi dan senjata kimia yang mengarah pada perlindungan lingkungan pada saat terjadi konflik. ${ }^{36}$

6. Convention on the prohibition of the development, production, stockpiling and use of chemical weapons and on their destruction 1993 atau Chemical Weapon Convention 1993

Selain itu terdapat pula Convention on the prohibition of the development, production, stockpiling and use of chemical weapons and on their destruction 1993 atau Chemical Weapon Convention 1993 yaitu konvensi yang melarang penggunaan senjata kimia yang pada Pasal 7 ayat (3) mengatur bahwa:

"Each State Party, during the implementation of its obligations under this Convention, shall assign the highest priority to ensuring the safety of people

\footnotetext{
${ }^{33}$ Desy Churul Aini, [et., al.].Op.Cit.

${ }^{34}$ ICRC, <https://ihl-data-bases.icrc.org/ihl/INTRO/460?OpenDocument> accessed 20 Oktober 2019.

${ }^{35}$ Nessia Marga Letta, 'Analisis Pengaturan Internasional tentang "Prinsip Maksud Damai” dan Bentuk Penerapannya dalam Kegiatan Antariksa' (2012) 9 Jurnal Analisis dan Informasi Kedirgantaraan.[77].

${ }^{36}$ Letta.Op.Cit.
} 
and to protecting the environment, and shall cooperate as appropriate with other State Parties in this regard". ${ }^{37}$

Berdasarkan pasal tersebut, konvensi mengatur bahwa dalam melakukan kewajibannya berdasarkan konvensi, negara anggota harus menjamin keamanan bagi manusia dan perlindungan terhadap lingkungan. Konvensi ini berlaku bagi konflik bersenjata internasional maupun internal.

7. Convention on the Prohibition of the Use, Stockpiling, Production and Transfer of Anti-Personnel Mines and on their Destruction 1997

Convention on the Prohibition of the Use, Stockpiling, Production and Transfer of Anti-Personnel Mines and on their Destruction 1997, juga mengatur bahwa segala sesuatu yang berkaitan dengan anti-personnel weapon atau ranjau harus memperhatikan dampaknya terhadap lingkungan termasuk salah satunya penghancuran ranjau aktif yang dulu digunakan dalam konflik bersenjata di negaranya, bahkan konvensi memberlakukan larangan penggunaan ranjau pada saat konflik bersenjata mengingat bahaya dari jenis senjata tersebut bagi manusia maupun lingkungan karena efek merusaknya. Konvensi ini berlaku baik pada konflik bersenjata internasional maupun internal.

\section{Kesimpulan}

Satwa terancam merupakan golongan satwa yang dilindungi berdasarkan Hukum Internasional. Satwa terancam merupakan bagian dari keanekaragaman hayati yang diatur oleh Hukum Lingkungan Internasional sebagaimana diatur dalam Konvensi Keanekaragaman Hayati tahun 1992. Terkait dengan eksistensi satwa terancam di daerah konflik bersenjata, Hukum Lingkungan Internasional dan Hukum Humaniter Internasional sama-sama memberikan pengaturan terkait perlindungannya walaupun bukan merupakan pengaturan yang mengatur secara langsung atau eksplisit terkait hal tersebut.

${ }^{37}$ Chemical Weapon Convention 1993. 


\section{Daftar Bacaan}

\section{Buku}

C . De Rover, To Server and To Protect: Acuan Universal Penegakan HAM (Raja Grafindo Persada 2000).

Daniella Dam-De Jong, International Law and Governance of Natural Resources in Conflict and Post-Coflict Situations (Cambridge University Press 2015).

J.G. Starke, Pengantar Hukum Internasional Edisi 2 (Sinar Grafika 1989).

Otto Soemarwoto, Indonesia dalam Kancah Isu lingkungan Global (Gramedia Pustaka Utama 1991).

Patricia Birnie, [et., al.], International Law and the Environment (Oxford University Press 2009).

Philippe Sands, [et., al.], Documents in International Environmental Law (Cambridge University Press 2004).

\section{Jurnal}

Desy Churul Aini, [et., al.], 'Environmental Protection in Armed Conflict According to International Humanitarian Law' (2018) 3 Tadulako Law Review.

Joseph P, Dudley, [et., al.], 'Effects of War and Civil Strife on Wildlife and Wildlife Habitats' (2002) 16 Conservation Biology.

Nessia Marga Letta, 'Analisis Pengaturan Internasional tentang "Prinsip Maksud Damai” dan Bentuk Penerapannya dalam Kegiatan Antariksa' (2012) 9 Jurnal Analisis dan Informasi Ke-dirgantaraan.

Soekotjo, 'Konservasi Ex-situ Cendana: Aplikasi dan Tantangannya' (2001) 5 Berita Biologi.

Viola Vincze, 'The Role of Customary Principles of International Humanitarian Law in Environmental Protection'(2017) 2017 Pécs Journal of International and European Law.

\section{Laman}

Centre of International Law National University of Singapore, 'Agreement on The Conservation of Nature and Natural Resources' (Centre of International Law National University of Singapore, $2009<\mathrm{https} / /$ cil.nus.edu.sg/ databasecil/1985-agreement-on-the-conservation-of-nature-and-natural- 
resources/> accessed 15 september 2019.

ICRC, <https://ihl-data-bases.icrc.org/ihl/INTRO/460?OpenDocument> accessed 20 Oktober 2019.

ICRC Blog, 'Protokol Tambahan I dan II Tahun 1977' (ICRC, 2012), <https:// blogs.icrc.org/indonesia/protokol-tambahan-i-dan-ii-tahun-1977/> accessed 29 Desember 2019.

Katie Reilly, 'The Congo's Civil War Is Wiping Out Gorilla Populations' (Time. com, 2016) <https://time.com/4282616/the-congos-civil-war-is-wiping-outgorilla-populations/> accessed 15 Agustus 2019.

Maya Wei-Hass, "The Animal Cost of War" (Smithsonianmag.com, 2018) <https:// www.smithsonianmag.com/science-nature/animal-cost-of-war-180967806/> accessed 15 September 2019.

Mongobay.com, 'Wars kill wildlife in Africa's protected areas, study finds' (Mongobay.com, 2018) <https://news.mongabay.com/2018/01/wars-killwildlife-in-africas-protected-areas-study-finds/> accessed 15 November 2019.

\section{Pengaturan Internasional}

Hague Convention (IV) 1907, Respecting the Laws and Customs of War on Land and Its Annex: Regulations concerning the Laws and Customs of War.

Geneva Convention (IV) 1949, Relative to the Protection of Civilian Persons in Time of War.

Additional to the Geneva Convention 1949, and Relating to The Protection of Victims of International Armed Conflict (Protocol I) 1977.

ASEAN Agreement on The Conservation of Nature and Natural Resources 1985 Convention on Biological Diversity 1992.

Council Directive 92/43/EEC of 21 May 1992 on the conservation of natural habitats and of wild fauna and flora.

Convention on the prohibition of the development, production, stockpiling and use of chemical weapons and on their destruction 1993. 
Yunia Utami: Pengaturan Perlindungan Satwa...

--halaman ini sengaja dibiarkan kosong-- 